\title{
Porosity Effects on Interlaminar Fracture Behavior in Carbon Fiber-Reinforced Polymer Composites
}

\author{
Issa A. Hakim 1,2,3*, Steven L. Donaldson4, Norbert G. Meyendorf ${ }^{2,5}$, Charles E. Browning ${ }^{6}$ \\ ${ }^{1}$ Department of Mechanical \& Aerospace Engineering, University of Dayton, Dayton, OH, USA \\ ${ }^{2}$ Fraunhofer-IKTS, Berlin, Germany \\ ${ }^{3}$ Department of Mechanical Engineering, Omar Al-Mukhtar University, El-Beida, Libya \\ ${ }^{4}$ Department of Civil \& Environment Engineering \& Engineering Mechanics, University of Dayton, Dayton, OH, USA \\ ${ }^{5}$ Department of Aerospace Engineering, Iowa State University, Ames, IA, USA \\ ${ }^{6}$ Department of Chemical \& Materials Engineering, University of Dayton, Dayton, OH, USA \\ Email: ^hakimi1@udayton.edu
}

How to cite this paper: Hakim, I.A., Donaldson, S.L., Meyendorf, N.G. and Browning, C.E. (2017) Porosity Effects on Interlaminar Fracture Behavior in Carbon Fiber-Reinforced Polymer Composites. Materials Sciences and Applications, 8, 170187.

https://doi.org/10.4236/msa.2017.82011

Received: December 16, 2016

Accepted: February 3, 2017

Published: February 6, 2017

Copyright (C) 2017 by authors and Scientific Research Publishing Inc. This work is licensed under the Creative Commons Attribution International License (CC BY 4.0).

http://creativecommons.org/licenses/by/4.0/

\begin{abstract}
Fiber-reinforced polymer composite materials have become materials of choice for manufacturing application due to their high specific stiffness, strength and fatigue life, low density and thermal expansion coefficient. However, there are some types of defects such as porosity that form during the manufacturing processes of composites and alter their mechanical behavior and material properties. In his study, hand lay-up was conducted to fabricate samples of carbon fiber-reinforced polymer composites with three different vacuum levels in order to vary porosity content. Nondestructive evaluation, destructive techniques and mechanical testing were conducted. Nondestructive evaluation results showed the trend in percentages of porosity through-thickness. Serial sectioning images revealed significant details about the composite's internal structure such as the volume, morphology and distribution of porosity. Mechanical testing results showed that porosity led to a decrease in both Mode I static interlaminar fracture toughness and Mode I cyclic strain energy release rate fatigue life. The fractographic micrographs showed that porosity content increased as the vacuum decreased, and it drew a relationship between fracture mechanisms and mechanical properties of the composite under different modes of loading as a result of the porosity effects. Finally, in order to accurately quantify porosity percentages included in the samples of different vacuum levels, a comparison was made between the parameters and percentages resulted from the nondestructive evaluation and mechanical testing and the features resulted from fractography and serial sectioning.
\end{abstract}




\section{Keywords}

Carbon Fiber Reinforced Composite, Nondestructive Evaluation, Porosity, Fatigue Fracture Behavior, Serial Sectioning

\section{Introduction}

Composite materials are manufactured from two or more materials to take advantage of desirable characteristics of the components. Composites usually consist of a reinforcing agent (fiber) and a compatible resin binder (matrix) to obtain desired properties. Advanced composites can be divided into laminates and sandwiches [1]. The laminates are layers or plies of composite materials bonded together, whereas, the sandwich is a multiple-layer composite structure consisting of a low-density core between thin laminate faces (skins) of composite materials. Currently, the two major techniques to fabricate blades composites are resin infusion and hand lay-up. During the manufacturing process, several types of manufacturing defects might emerge in the composite such as porosity, fiber waviness, ply waviness, debonding between the fibers and the matrix and inclusions. Defects can lead to severe degradation in the composite properties [1].

Porosity is usually determined as the distribution of microscopic interfacial micro-voids located in the matrix between plies of fibers and scattered over the volume of composite laminate. It invariably gets introduced in polymer matrix composite materials during the fabrication process [2]. Porosity cannot be totally avoided in this type of material; the presence of such defects beyond a certain limit can be highly detrimental to the mechanical properties of the final product and hence their performance as a structural component. Porosity above a critical level affects static and fatigue strength of composite parts and a greater susceptibility to water penetration and environmental effects. During subsequent loading, porosity acts as nuclei of further damage growth resulting in strength degradation. Lowest possible porosity levels are thus essential for ensuring the performance of fiber-reinforced composite structures [2].

However, porosity results from small bubbles trapped in the resin during impregnation of the fiber reinforcement with resin or during lay-up. Porosity has a detrimental effect on the matrix-dominated properties, such as interlaminar shear strength, compressive strength and modulus, and bending properties. Mechanical properties decrease as the porosity content increases; for example, interlaminar shear strength values decrease by about $34 \%$ for carbon/epoxy fabric laminates when the void content increases from $0.55 \%$ up to $5.60 \%$ [3]. One of the most important properties of fiber composite that can be affected by porosity is the composite resistance to delamination, as measured by interlaminar fracture toughness. The presence of delamination may lead to a loss of stiffness or even to complete fracture [1]. The effect of various curing pressure results in different porosity contents influence the mechanical properties of carbon/epoxy laminates [4]. Common methods for creating porosity in composite materials 
are vacuum pressure, water spray, solvent spray and micro balloon.

The objectives of the present work are: 1) to induce porosity of varied levels in carbon fiber-reinforced composite by varying the vacuum level; 2) to apply eight nondestructive evaluation methods to quantify porosity content in all directions of the carbon fiber composite samples; 3 ) to investigate the effect of porosity on delamination behavior under static and fatigue Mode I (opening mode); 4) to conduct the destructive test of serial sectioning through-thickness in order to understand the porosity's shape, size and distribution inside the carbon fiberreinforced composite samples; 5) to implement fractography to the fractured surfaces of the samples tested by static and fatigue Mode I to help understand the fracture mechanisms of carbon fiber composite under these tests; 6) to compare all parameters, features, percentages, and values resulted from all conducted approaches to quantify the porosity effects on interlaminar fracture behavior in carbon fiber-reinforced composite.

\section{Methodology}

\subsection{Panel Fabrication}

In this study, panels of carbon fiber-reinforced polymer composites were fabricated with 60\% Fiber Weight Fraction (FWF) and 40\% Resin Weight Fraction (RWF) from unidirectional carbon fiber Toray T700, EPON ${ }^{\mathrm{TM}} 828$ epoxy resin, EPIKURE curing agent EPIKURE 3223 (hardener) and non-porous Teflon 0.0005 mil FEP film, no adhesive as the delamination precrack. The carbon fiber was chosen because of its high strength and modulus and it is cost effective and popular. Epoxy resin was selected because of its excellent mechanical strength, dimensional stability, strong bond with fiber and good chemical and heat resistance with low shrinkage.

Hand lay-up vacuum bagging set up shown in Figure 1 was used to fabricate

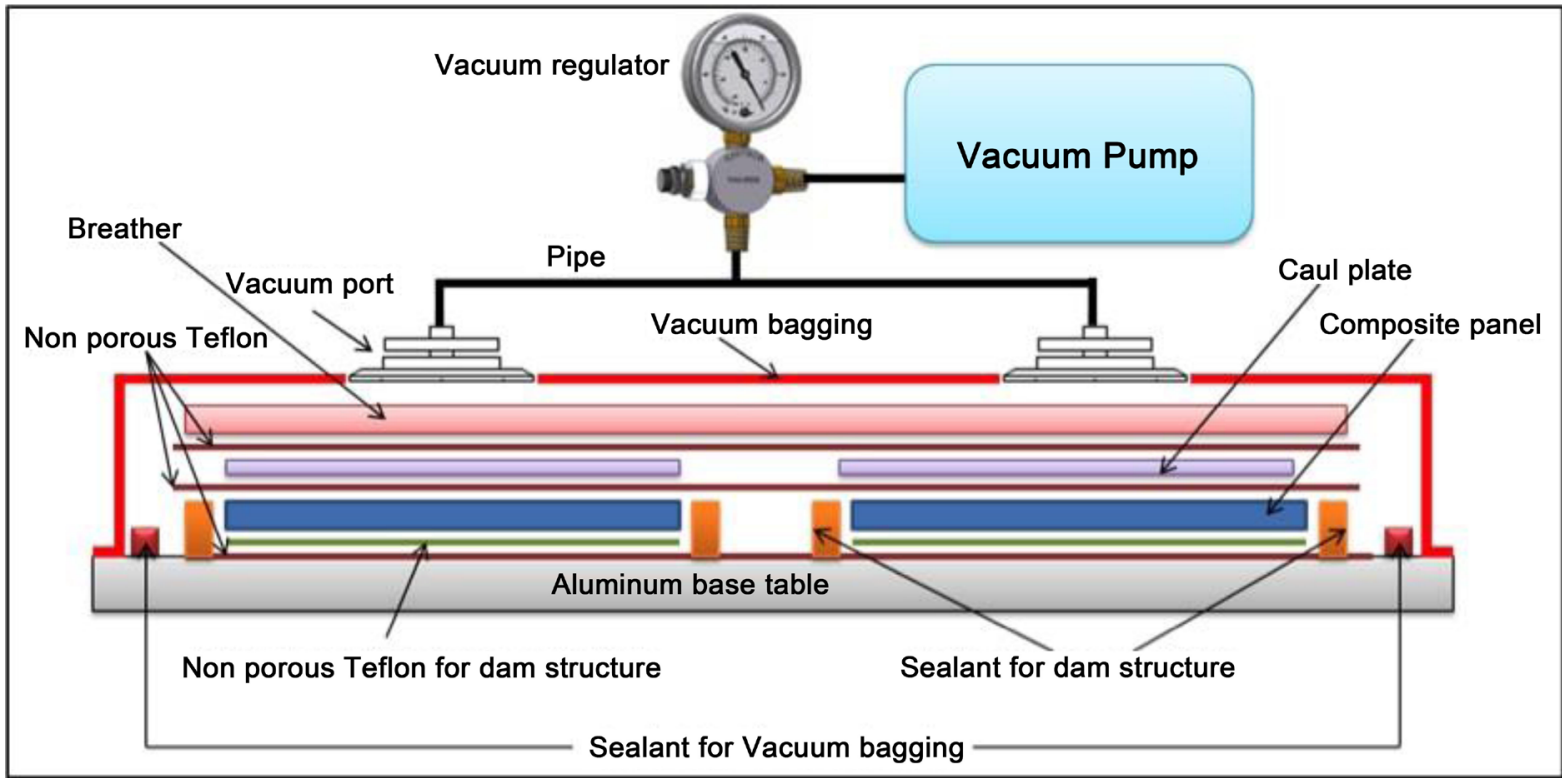

Figure 1. VB setup for fabricating the S1-HM/Epoxy composite panels [3]. 
samples of carbon fiber-reinforced polymer composite with three different vacuum levels, indicated High $(-686 \mathrm{mmHg})$, Moderate $(-330 \mathrm{mmHg})$ and Poor $(0 \mathrm{mmHg})$ in order to vary porosity content since it can be adjusted to induce different porosity levels in the resulted composite material. Hand lay-up manufacturing process was elected due to its mechanical pressure compacts the laminate, removes air, humidity and excess resin, which all compromise the curing process and the performance of the finished part.

A total of six panels were fabricated (three different vacuum levels); each two panel set was fabricated at the same vacuum, which was expected to represent a fixed porosity volume fraction. Figure 2 shows the steps of fabrication process of panel. After the vacuum bagging process, the panels were left at room temperature for more than one month.

As soon as the panels cured, the first step was to cut each panel into Mode I samples according to ASTM standard [5] [6]. Mode I samples were 1" wide and 6 " long along the fiber direction. The next step was to grind the edges of each sample with sand paper to remove machining notches. Then, the length of each sample, the width and thickness at three locations along the length were measured. Both steps are presented in Figure 3.

\subsection{Nondestructive Methods}

In this study, eight different nondestructive evaluation methods were conducted

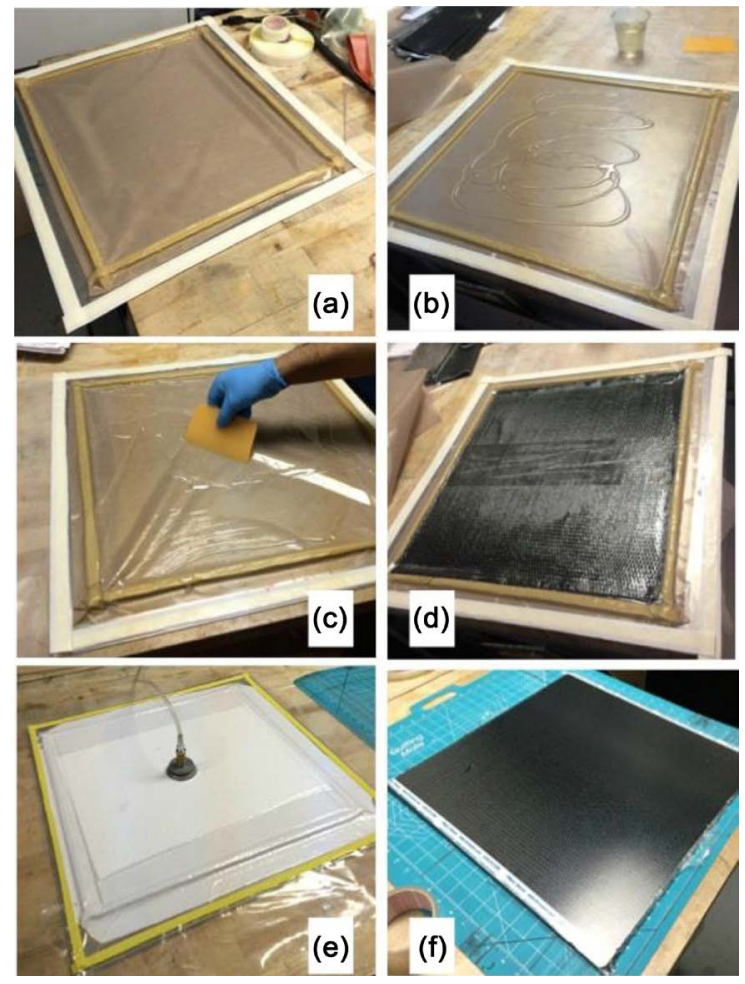

Figure 2. Hand laying up steps: (a) Dam structure (b) Resin laying up (c) Resin distributing (d) Placing the Teflon insert at the panel mid-plane; on top of four layers (e) Placing breather and vacuum bag, and applying vacuum bagging for 24 hours except for poor vacuum panels (f) Panel final shape ready to cure and to be cut. 
in Germany at Fraunhofer-IKTS, Nanotest and BAM in Berlin and TU Dresden, including imaging nondestructive evaluation methods: X-Ray laminography, ultrasonic microscopy, high frequency eddy current, pulse thermography (PT), pulse phase thermography (PPT) and lock-in-thermography (LIT), and averaging nondestructive evaluation techniques: X-Ray refraction and thermal conductivity measurements. The experimental set up and testing procedures of all eight nondestructive evaluation methods are described in [7] [8].

\subsection{Serial Sectioning}

The destructive method of serial sectioning (SS) is the most reliable testing method for evaluating porosity and other defects in composite materials since it exposes the composite's internal structure and provides a clear idea about the type, shape, size, distribution and location of any defects. Samples from poor, moderate and high vacuum levels were serial sectioned through-thickness into three layers at the University of Dayton's Research Institute (UDRI) as shown in Figure 4.

\subsection{Mechanical Testing and Fractography Analysis}

Mode I (Double Cantilever Beam-DCB) was conducted under static and fatigue conditions at UDRI. Static test was implemented to study the effects of porosity on Mode I interlaminar fracture toughness following the ASTM standard D5528 [5] [9]. Fatigue test was conducted to study the effects of porosity on fatigue delamination crack growth initiation (G-N) behavior of Mode I following the

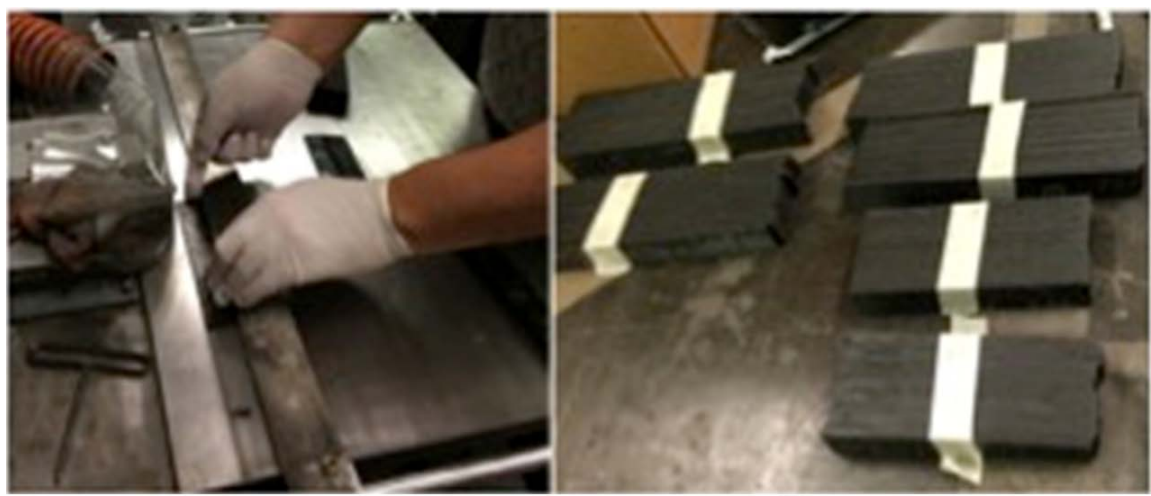

Figure 3. Cutting Samples to the final shape.
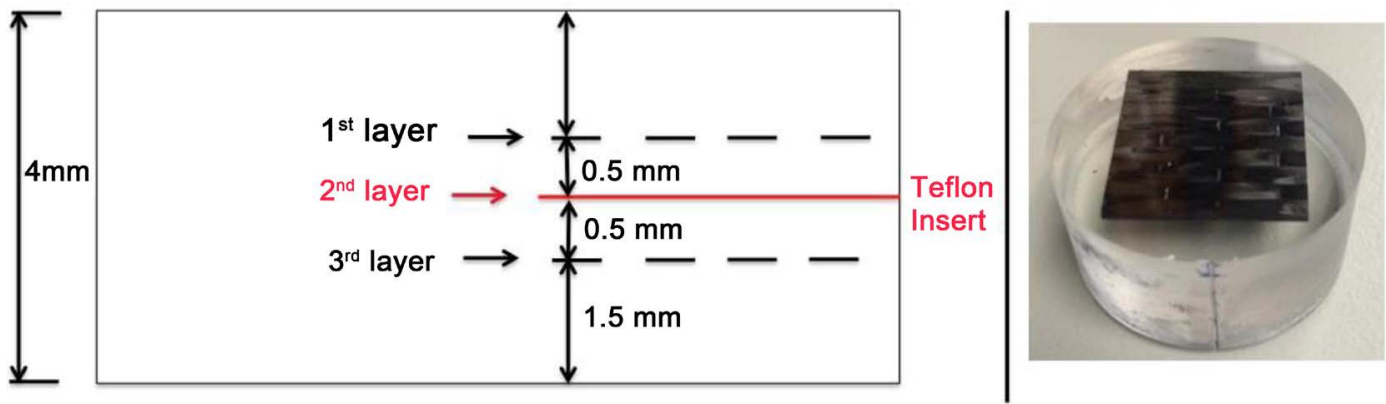

Figure 4. Schematic showing the layers serial sectioned and an image showing a sample being tested. 
ASTM standard D6115 [6] [9].

Fractography was the final part conducted in this research to characterize the fractured surfaces of the samples tested by static and fatigue Mode I using the Hitachi S-4800 High Resolution Scanning Electron Microscope (SEM) at UDRI. Samples were chosen from the three vacuum levels, and they were cut into a length, which included the fractured region, then each sample was opened to two parts. Both parts were bonded to a metallic stub using copper tape. In order to make the sample surface conductive, the fractured surface of each sample was sputtered by gold-palladium using a Denton Desk II Sputter coater. The fractographic images of the fractured surfaces of each sample were obtained at several magnification levels from $30 \times$ to $80,000 \times$ [3] [10].

\section{Results}

\subsection{Nondestructive Methods}

\subsubsection{Thermal Conductivity Measurements}

The parameter of thermal conductivity through-thickness increased as the vacuum level decreased as a results of porosity effects: $0.64 \mathrm{~W} / \mathrm{mK}, 0.69 \mathrm{~W} / \mathrm{mK}$ and $0.75 \mathrm{~W} / \mathrm{mK}$ for the vacuum levels of poor, moderate and high respectively. In comparison with the other composite longitudinal and transverse directions, thermal conductivity in through-thickness direction was the lowest conductive one because porosity can easily get in between fiber layers and isolate them. Thermal conductivities were: $0.75 \mathrm{~W} / \mathrm{mK}, 0.80 \mathrm{~W} / \mathrm{mK}$ and $3.75 \mathrm{~W} / \mathrm{mK}$ throughthickness, transverse and longitudinal directions respectively [7].

\subsubsection{Thermography}

The results of PT, PPT-amplitude and PPT-phase detected porosity content decreased as the vacuum level increased. As shown in Figure 5, porosity percentage decreased as vacuum level increased as follows: $3.41 \%, 2.78 \%$ and $1.11 \%$ for the vacuum levels of poor, moderate and high respectively [7].

LIT-amplitude and phase results showed how deep the porosity was in the material. In Figure 6, the large spots are signals due to artificial wall thing by removing of material locally. This indicates the depth sensitivity of LIT in comparison with the contrast from the materials inhomogeneity respectively [7].

\subsubsection{Eddy Current}

Eddy current images showed only textile structure information such as carbon fiber orientation as shown in Figure 7. A defect such as porosity was not detected. In general, it is difficult for eddy current to detect porosity in carbon fiber composites with woven structure. The eddy current images showed some abnormalities, which is porosity on the sample surface. However, eddy current might be applicable to detect porosity in homogenous structure only.

\subsubsection{Ultrasonic Microscopy}

Parameters such as back scattering and back reflection were observed as ultrasonic waves travel deeper in the sample and hit defects or regions of lower den- 
sity. Some dark spots (means higher backscatter signal) appeared on the ultrasonic images as presented in Figure 8. That represents defects like delaminations or regions of reduced density that are related to porosity in the samples.
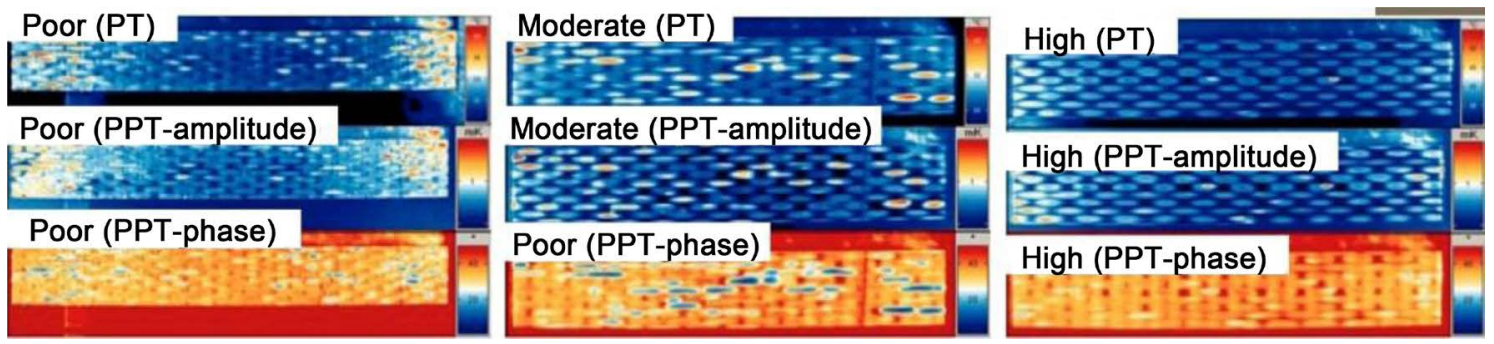

Figure 5. An overview showing porosity difference in three vacuums PT and PPT techniques [7].

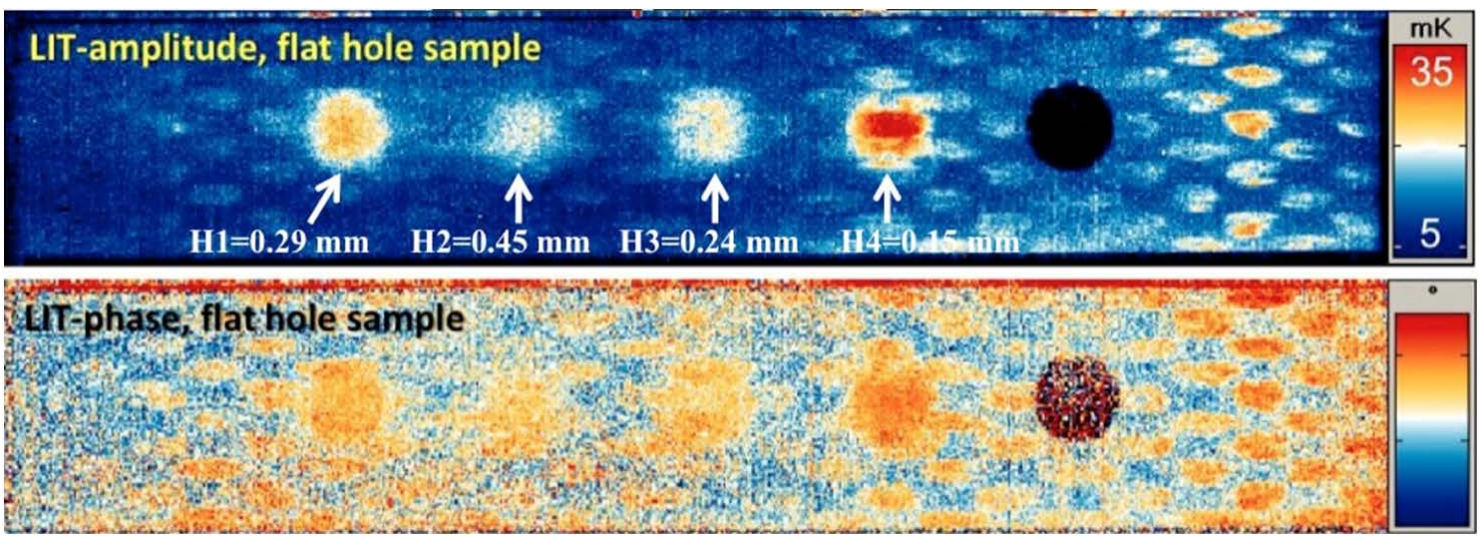

Figure 6. LIT-amplitude and phase images showing spots with reduced wall thickness [7].

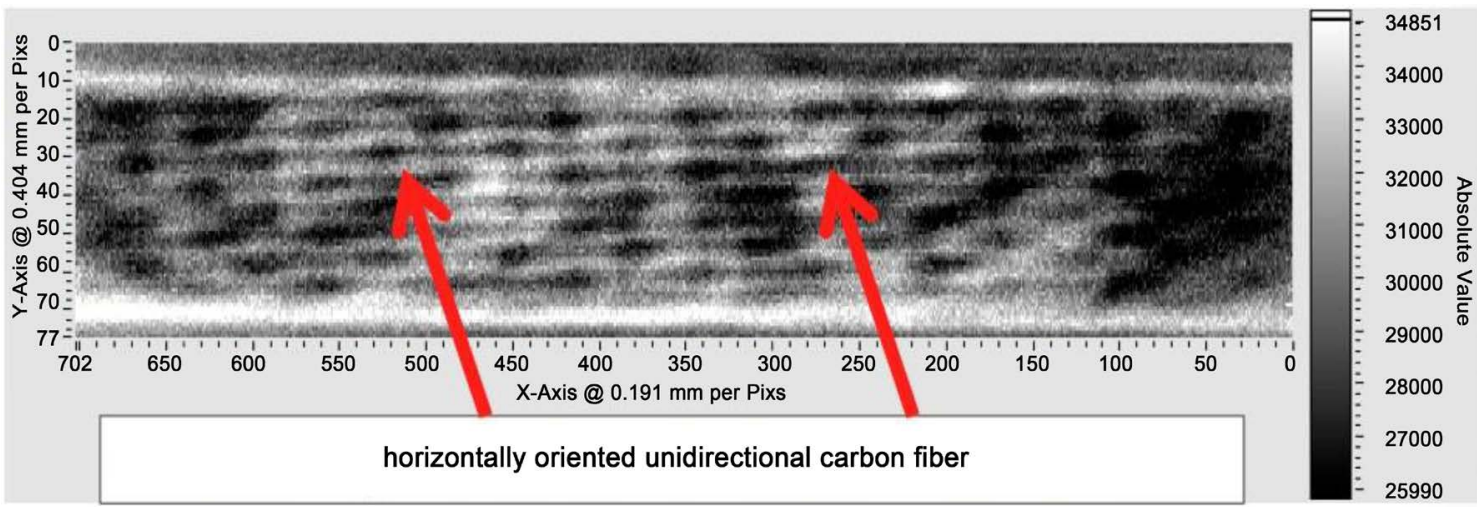

Figure 7. Fiber orientation and composite structure.

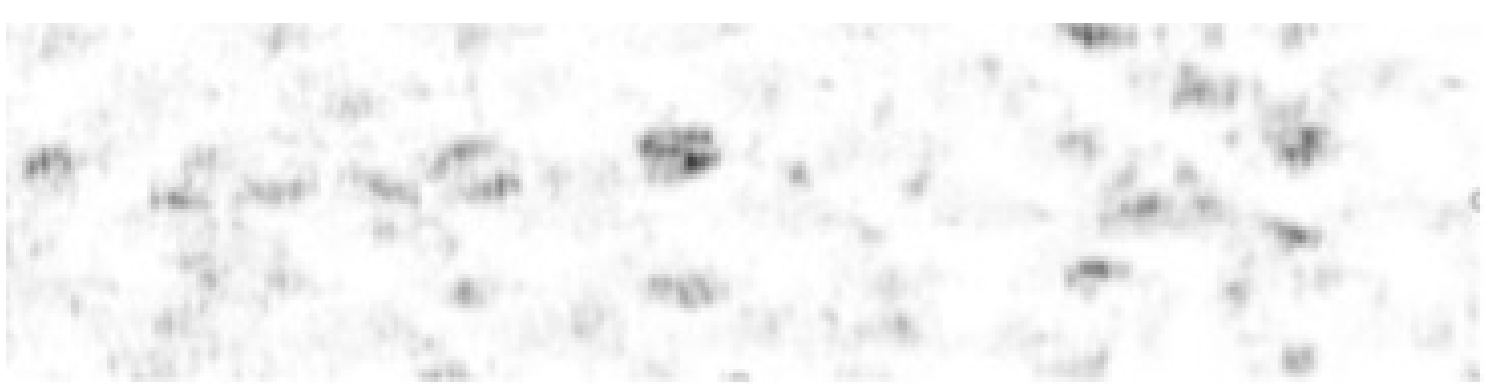

Figure 8. Ultrasonic microscopy shows dark spots, a similar pattern seen in thermography. 


\subsubsection{X-Ray Computed Planar Tomography (Laminography)}

This method was conducted for critical regions of porosity identified in samples from each vacuum level by other nondestructive evaluation methods. During the $\mathrm{X}$-Ray laminography scanning process, a sequence of radiographic images with different angles relative to the source was acquired. A single laminographic scan produced a data set consisting of about 1180 images $(1024 \times 514$ pixel), with 100 $\times 100 \mu \mathrm{m}$ pixel size. The laminographic scan was conducted and then a sequence of images was acquired and after the acquisition, this sequence of 2-D data set of images was reconstructed using a filtered back projection algorithm in order to create a 3-D data set containing depth information as Figure 9 reveals [8].

Figure 9 shows the resulting data set illustrated in three different planes. The $x-y$-plane represents only one slice (thickness $0.1 \mathrm{~mm}$ ) of the sample volume. The $\mathrm{x}-\mathrm{z}$ - and $\mathrm{y}-\mathrm{z}-$ planes represent single cross sections of the volume, as well, but in different orientation. Especially in the $x$-y-plane, the lack of material (bright areas) is clearly visible. As the tows were orientated along the scanning (x-) direction, they were cancelled out by the reconstruction algorithm. Furthermore, due to the limited angle of the laminographic scan (cross) artifacts arise which lead to a distortion of the porosity representation in z-direction. This distortion has to be considered when quantifying indications for defects or zones with enhanced porosity. To quantify defects in the resulting data set, a histogram was created to characterize the area fraction of reduced density that might be related to porosity in each image and then the porosity volume fraction as the average of the porosity area fraction in all the layers of a specific sample following the same methodology used in serial sectioning [8].

\subsubsection{X-Ray Refraction}

$\mathrm{X}$-Ray Refraction tests are selective to small spherical defects and therefore be able to quantify porosity, was conducted in horizontal and vertical orientations to the fiber-matrix interfaces. For each sample, an area of about $25 \mathrm{~mm} \times 25 \mathrm{~mm}$ was tested. The samples were scanned in a grid with step widths between

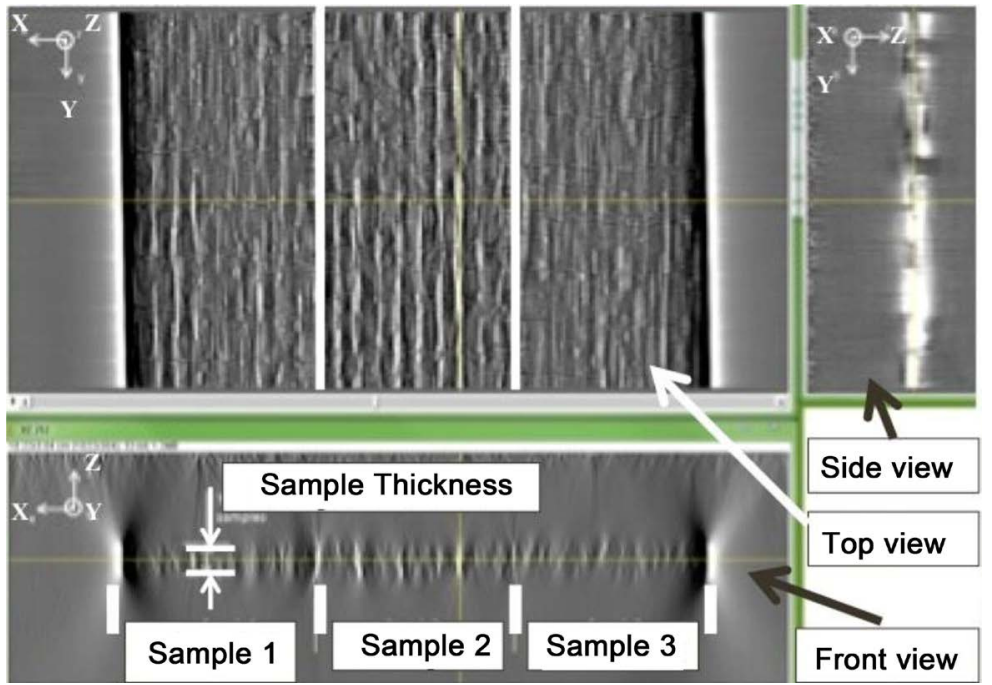

Figure 9. Resulting 3D data set of laminographic scans [8]. 
measurement points of $\Delta x=1.5 \mathrm{~mm}$ and $\Delta y=50 \mu \mathrm{m}$. From the acquired data, a topographic map of the relative specific surface was created and the average value determined. Figure 10 shows such a topographic map of three samples in vertical orientation: one sample of each vacuum level [8].

Figure 10 shows that poor vacuum samples have the highest amount of inner surfaces and the high vacuum samples have the lowest. The same observation can be made when analysing the average value of the relative specific surface over all measurements. A summary of porosity percentages in horizontal and vertical orientations in Table 1.

The difference in results between the horizontal and vertical orientations is due to the influence of the fibers. In horizontal orientation, the interface between the unidirectional carbon fibres and the matrix contributed to the refraction signal while in vertical orientation it does not. However, in both orientations, the relative specific surface increased with lower vacuum level. This is caused by the higher amount of defects in the poor and moderate vacuum samples. The increase in relative specific surface from high to moderate vacuum level is about the same for both orientations, indicating a random orientation of the additional defects. In contrast, the increase from moderate to poor vacuum level was much higher in horizontal orientation, indicating a preferred orientation of the further additional defects parallel to the fiber orientation [8].

\subsection{Serial Sectioning}

The destructive technique of serial sectioning (SS) was undertaken in this study to characterize porosity following the same procedure in the literature [3] [10]. Samples were selected from several locations in each panel. Each sample was polished into three layers through thickness as shown in Figure 4; layers near the

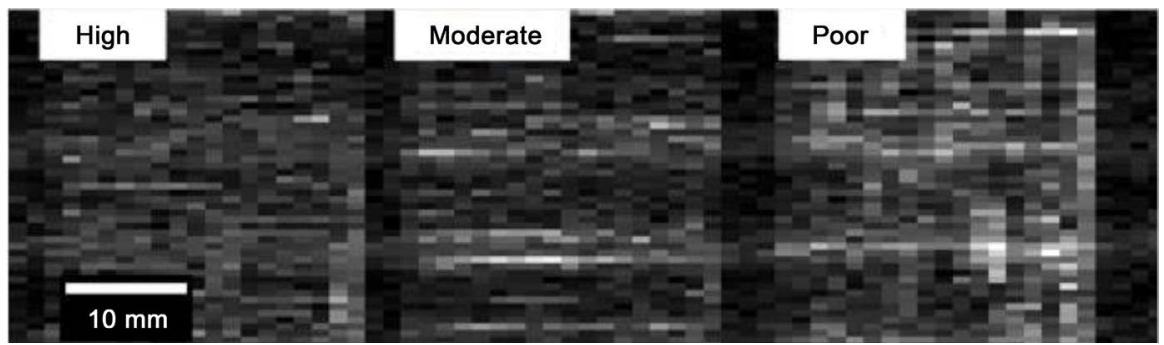

Figure 10. Topographic map of relative specific surface for samples in vertical orientation from each vacuum [8].

Table 1. A summary of porosity effect on interlaminar fracture behavior measured by all approaches [8].

\begin{tabular}{|c|c|c|c|c|c|c|c|}
\hline \multirow{2}{*}{ Vacuum Level } & \multirow{2}{*}{$\begin{array}{l}\text { Discontinuities Including } \\
\text { Porosity (Imaging } \\
\text { Nondestructive) }\end{array}$} & \multirow{2}{*}{$\begin{array}{c}\text { Thermal } \\
\text { Conductivity } \\
(\mathrm{W} / \mathrm{mK})\end{array}$} & \multicolumn{2}{|c|}{$\begin{array}{c}\text { Inner Surfaces } \\
\text { (X-Ray Refraction) }\end{array}$} & \multirow{2}{*}{$\begin{array}{l}\text { Porosity } \\
\text { (SS) }\end{array}$} & \multicolumn{2}{|c|}{ Mode I $\left(\mathrm{G}_{\mathrm{IC}}\right) \mathrm{kJ} / \mathrm{m}^{2}$} \\
\hline & & & Horizontal & Vertical & & Static & Fatigue at $\mathrm{N}=10^{6}$ \\
\hline Poor & $3.70 \%-4.80 \%$ & 0.64 & $1.05 \%$ & $0.36 \%$ & $3.43 \%$ & 0.45 & 0.005 \\
\hline Moderate & $3.10 \%-4.39 \%$ & 0.69 & $0.95 \%$ & $0.33 \%$ & $1.77 \%$ & 0.44 & 0.006 \\
\hline High & $1.30 \%-2.10 \%$ & 0.75 & $0.87 \%$ & $0.23 \%$ & $1.49 \%$ & 0.52 & 0.010 \\
\hline
\end{tabular}


midsection of each sample where the Teflon insert exists and other layers above and below the midsection layer. Digital microscope KYENCE was used to examine each polished surface with $25 \times$ magnification. The software of Image Pro Plus was used to quantify porosity percentage for each layer. For each sample, porosity percentage was determined by taking the average of the porosity area fraction of the three layers in that sample. The final value for the porosity area fraction of each vacuum was taken as an average of all the chosen samples, with each sample sectioned and polished three times to obtain representative measurements. Based on 15 measurements each, the average values are: 3.43\%, $1.77 \%$ and $1.49 \%$ for the vacuum levels poor, moderate and high respectively.

Most of the samples showed higher porosity area fraction in the layers around the midsection where the Teflon insert exists. In addition, the average porosity area fraction or what can be called average porosity volume fraction increased with decreasing vacuum because more vacuum pressure forces the air bubbles (porosity) to diffuse toward the edges of the panel or dissolve inside the epoxy matrix. Therefore, serial sectioning is a reliable technique that showed distinct and significant variations in porosity content between the three vacuum levels.

Another significant observation is that, there are variations in the porosity area fraction of samples at different locations in the same panel. Hence, higher porosity area fraction of samples toward the edges of high vacuum panels compared to porosity area fraction of samples toward the panel center. However, this was not the case in poor and moderate vacuum panels vacuums, where low to no variations was seen on the porosity area fraction of samples from the center to the edges of the same panel. This is because in the case of high vacuum, the panels were subjected to more vacuum pressure at the panel center than the panel edges, considering the fact that vacuum ports were located at the panel center. However, in the case of lower vacuums, in particular poor vacuum, the vacuum pressure was low at all locations on the entire panel, and therefore all locations throughout the panel were subjected to fairly the same amount of vacuum pressure. Hence, the samples showed more consistent porosity area fraction [10].

As for the porosity shapes and sizes formed at different vacuums in these fabricated composites, they can be considered as resin porosity because mostly they existed in resin rich regions, such as between the fibers tows. In addition, it was observed that a lower vacuum resulted in larger size porosity. Moreover, porosity existed in spherical and cylindrical shapes, and the lower the vacuum the more the cylindrical porosity existed in the laminate. That is because the cylindrical shapes emerge in the lower vacuum laminates because of coalesce of much spherical porosity which were diffusing under the force of vacuum pressure, but the forces were not enough to diffuse them toward the edges of the panel and instead they coalesced together to form large cylindrical porosity. Another belief is that they existed as longitudinal air bubbles trapped between the fiber tows because vacuum pressure was not enough to dissolve the porosity inside the resin matrix or diffuse porosity outside the laminate. These types of cylin- 
drical porosity were common in the poor and moderate vacuum laminates [10].

The midsection layer is important as it represents the location where initiation and propagation of cracks will occur in subsequent mechanical testing. The midsection layers showed higher porosity area fraction than other layers. The values are based on five measurements each one. Figure 11 reveals the features investigated in this study such as different shapes, sizes and locations of porosity and regions rich with fiber or resin, which dramatically dictate porosity content in the composite material.

\subsection{Mechanical Testing and Fractography}

\subsubsection{Mode I-DCB Static Test and Fractography}

The purpose of conducting the static test was to study the effect of porosity on Mode I interlaminar fracture toughness $G_{I c}$ because composites have high inplane tensile strength, but low through-thickness properties. Hence, throughthickness stresses in laminated composites may initiate delamination. After delamination onset, the subsequent propagation is not controlled by the throughthickness strength any more, but by interlaminar fracture toughness. If the interlaminar fracture toughness is expressed in terms of energy release rate, the delamination will propagate when the energy release rate reaches a critical value $G_{c}$. This value is then called mode I interlaminar fracture toughness $\left(G_{I c}\right)$.

Based on specimens tested in static Mode I, the mean value of static $G_{I c}$ at poor vacuum was $0.45 \mathrm{~kJ} / \mathrm{m}^{2}$, moderate vacuum was $0.44 \mathrm{~kJ} / \mathrm{m}^{2}$, and high vacuum was $0.52 \mathrm{~kJ} / \mathrm{m}^{2}$ since reducing vacuum level produces higher porosity percentage and thicker resin layers between fiber plies. High porosity content decreases the material's strength and resistance to crack propagation. Figure 12 shows the higher the vacuum (lower porosity content) the higher the force required to open samples and propagate the crack in Mode I static test. However, poor and moderate vacuums (higher porosity content) did not require much force to initiate and grow the crack.

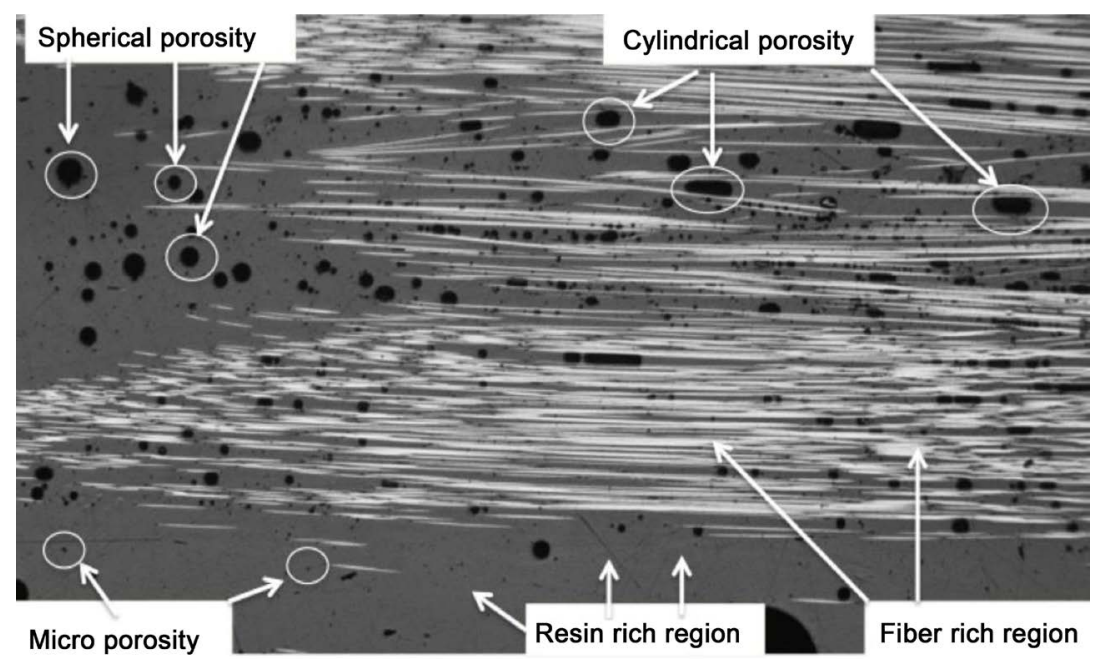

Figure 11. 25× magnification micrographs showing different features and types of porosity. 
Fractography was conducted to help understand the fracture mechanisms of carbon fiber composite samples tested under static and fatigue Mode I. Hence, relations between the fracture surfaces and the mechanical properties of composite material was drawn and the differences in the fractographic features between panels fabricated at different vacuum levels and between Mode I static was observed.

Fractographic images for static Mode I revealed many significant features that are labeled in Figures 13-15. Also, Fractographic analysis showed a smooth clean surface of the fiber and matrix with a very brittle cleavage fracture surface at the resin rich regions forming a $90^{\circ}$ angle with the loading direction because the crack growth was primarily in the resin-rich midsection layer between the fiber plies [10]. Also, fiber imprints on the matrix reveals there was fiber debonding associated with delamination.

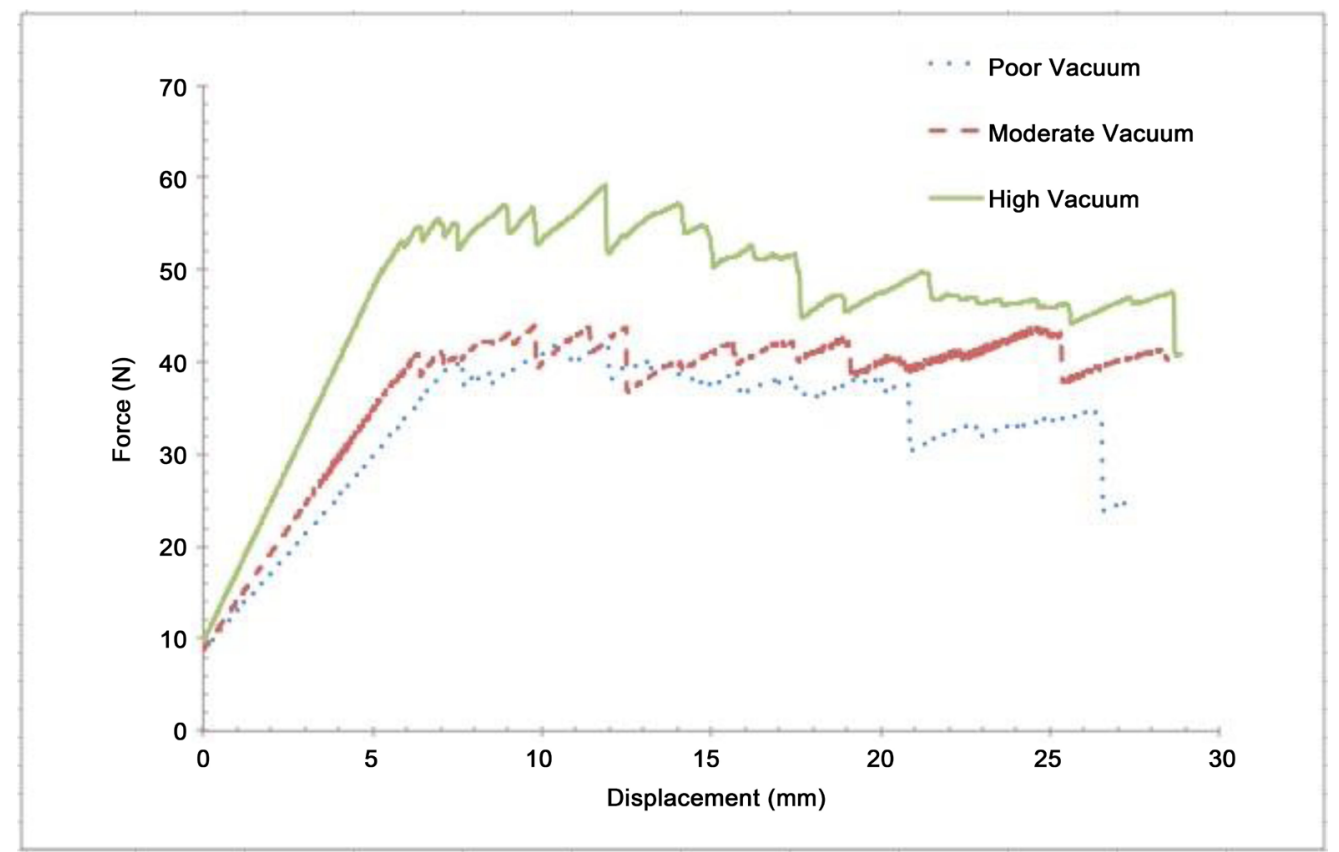

Figure 12. Load-displacement curve for samples from the three vacuums.
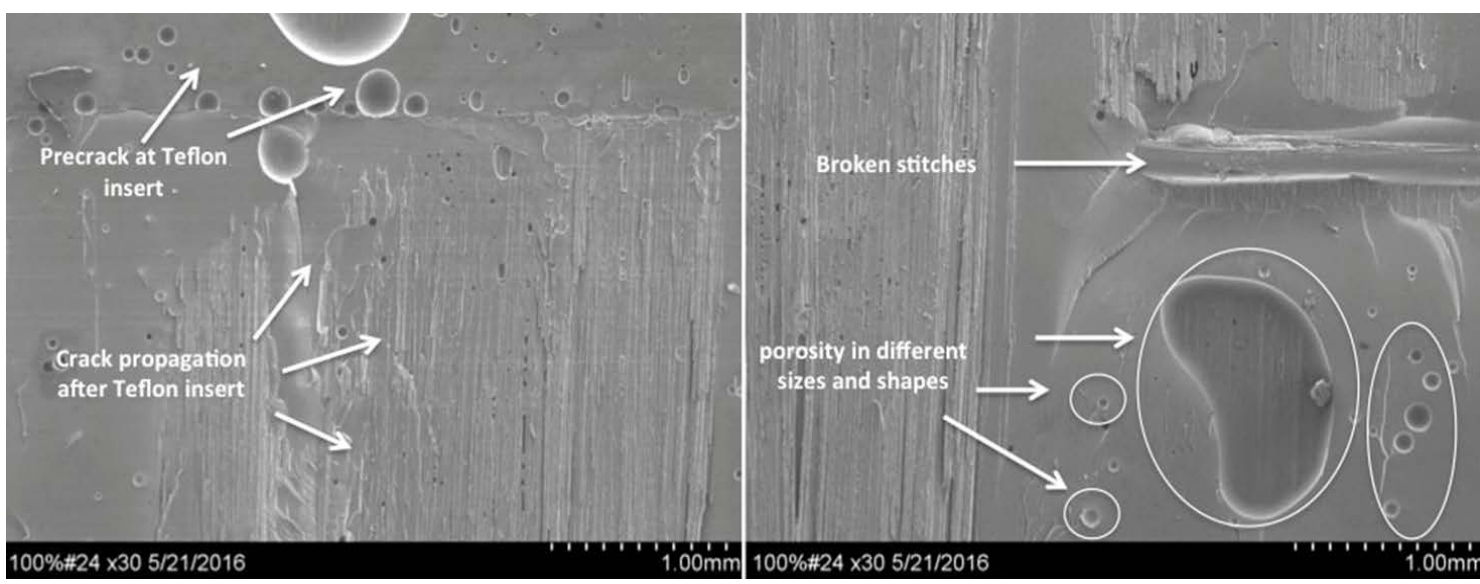

Figure 13. SEM micrographs of poor vacuum sample fracture surface under static mode I. 


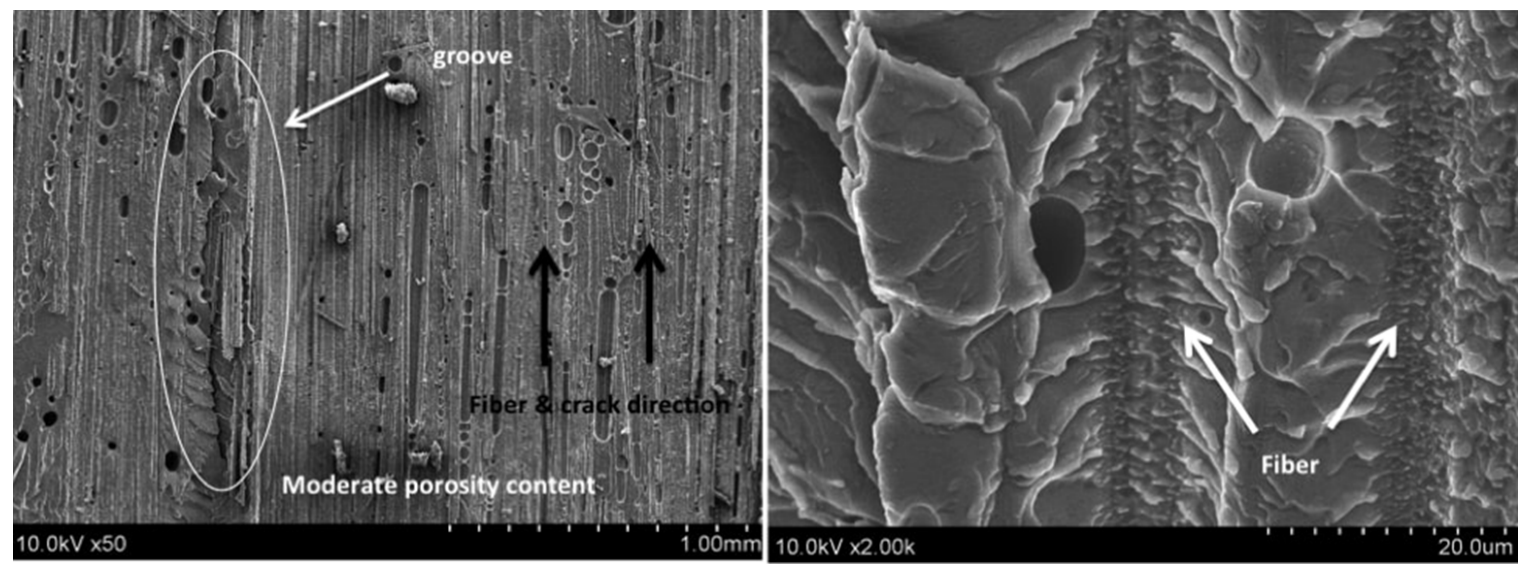

Figure 14. SEM micrographs of moderate vacuum sample fracture surface under static mode I.
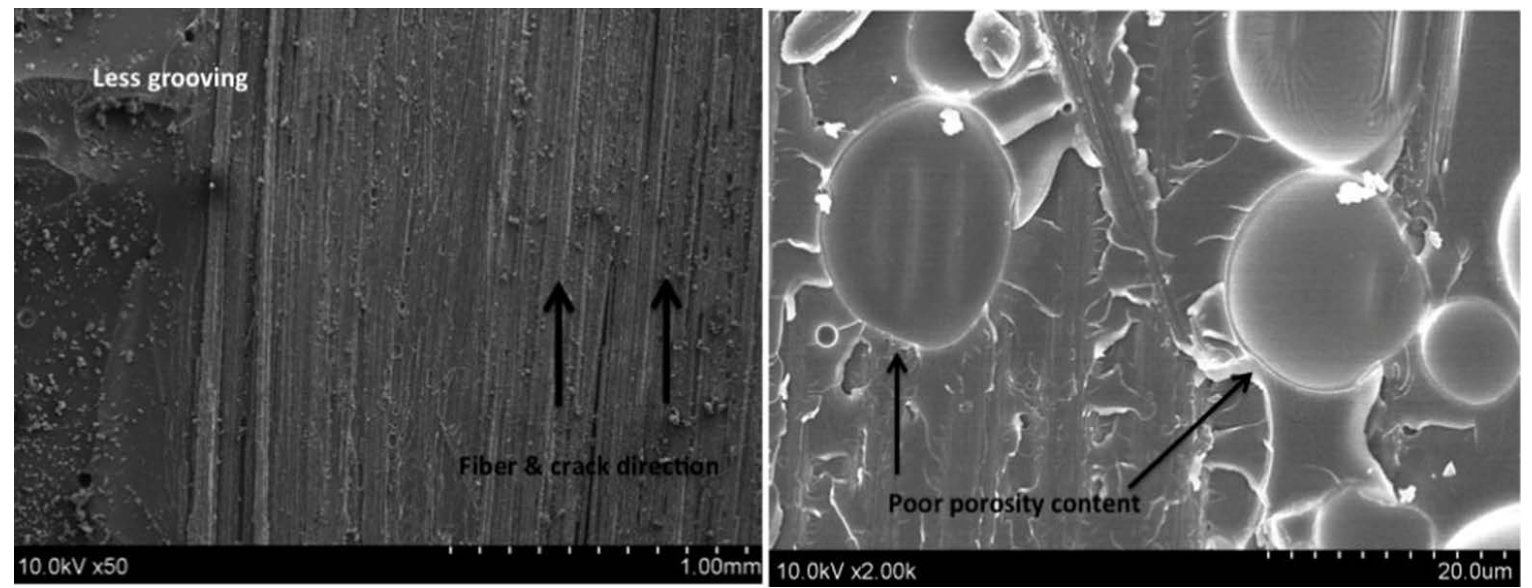

Figure 15. SEM micrographs of high vacuum sample fracture surface under static mode I.

\subsubsection{Mode I-DCB Fatigue Test and Fractography}

$G_{\text {Imax }}$ of fatigue Mode I was calculated following ASTM standard D6115. Samples were statically precracked for the fatigue test, and the crack length (a) was measured. The precracked samples were cycled in displacement control between $\delta_{\min }$ and $\delta_{\max }$ at a frequency of $5 \mathrm{~Hz}$ using $0.1 R$-ratio $\left(\delta_{\min } / \delta_{\max }\right)$. Maximum and minimum loads and the number of cycles were recorded during the test. The number of displacement cycles at which the visual onset of delamination growth accrued was recorded $N^{v i s}$, and the corresponding $G_{I \max }$ was calculated by MBT- $\Delta$ Equation (1). Where $G_{\text {Imax }}$ is the maximum cyclic mode I strain energy release rate, $P_{\max }$ is the maximum cyclic load, $\delta_{\max }$ is the maximum cyclic displacement, $b=25.4 \mathrm{~mm}$ is the width of DCB specimen, $a$ is the delamination length at $\mathrm{N}=1$, it varied from $63.5 \mathrm{~mm}$ to $78.4 \mathrm{~mm}$ and $\Delta_{a v}$ is average value of $\Delta$ from the static test [6].

$$
G_{I \max }=\frac{3 P_{\max } \delta_{\max }}{2 b\left(a+|\Delta|_{a v}\right)}
$$

For each individual vacuum level, poor, moderate and high, each tested sample $i$ gave one point $\left(N_{i}^{i s}, G_{\operatorname{Imax}}\right)$ on the $\left(G_{\max }-N\right)$ curve for that vacuum. Six samples were tested using different maximum cyclic displacements $\delta_{\max }$ in order 
to obtain the full $G-N$ curve for a specific vacuum. The visual observation approach of crack onset was conducted since it is the most accurate approach. Figure 16 shows the fatigue $\left(G_{\max }-N\right)$ curves for the poor, moderate and high vacuum levels between $3 \times 10^{2}$ to $10^{6}$ cycles. Many current composite applications are expected to experience $10^{6}$ fatigue cycles over a 20 to 30 years, which will be considered in the values in Table 1 . For each vacuum, a power law ( $G_{\text {Imax }}$ $=a N^{b}$ ) was estimated using a regression analysis for the data points. An obvious variation in the maximum cyclic mode I strain energy release rate $G_{\operatorname{Imax}}$ and the number of cycles to delamination onset among the three vacuum levels. For instance, $0.05 \mathrm{~kJ} / \mathrm{m}^{2}$ energy requires $3 \times 10^{3}$ cycles for delamination onset to occur at poor vacuum; but, it needs $2.2 \times 10^{4}$ cycles at moderate vacuum and $6 \times 10^{5}$ cycles at high vacuum although points sometimes scatter around the curves. Therefore, a larger number of cycles is required in the high vacuum than that of the moderate; similarly, a larger number of cycles is required in the moderate vacuum than that of poor vacuum. Shorter fatigue life is due to higher porosity content. The three samples at $1 \times 10^{6}$, one from each vacuum, in Figure 16 were "run out" samples, which means the number of cycles exceeded $1 \times 10^{6}$ cycles without any delamination onset, and after which the test was stopped. Such samples took about a week in continuous cycling.

Figures 17-19 revealed fractographic micrographs of fracture surfaces of samples from the three vacuums after Mode I fatigue test. The micrographs showed a general trend that the lower the vacuum the higher porosity content, the more these features become obvious, especially the debris and the river (ramified) cracks. These features in particular porosity content can be correlated to the result shown in Figure 16 that the porosity is an effect on interlaminar fracture behavior [10].

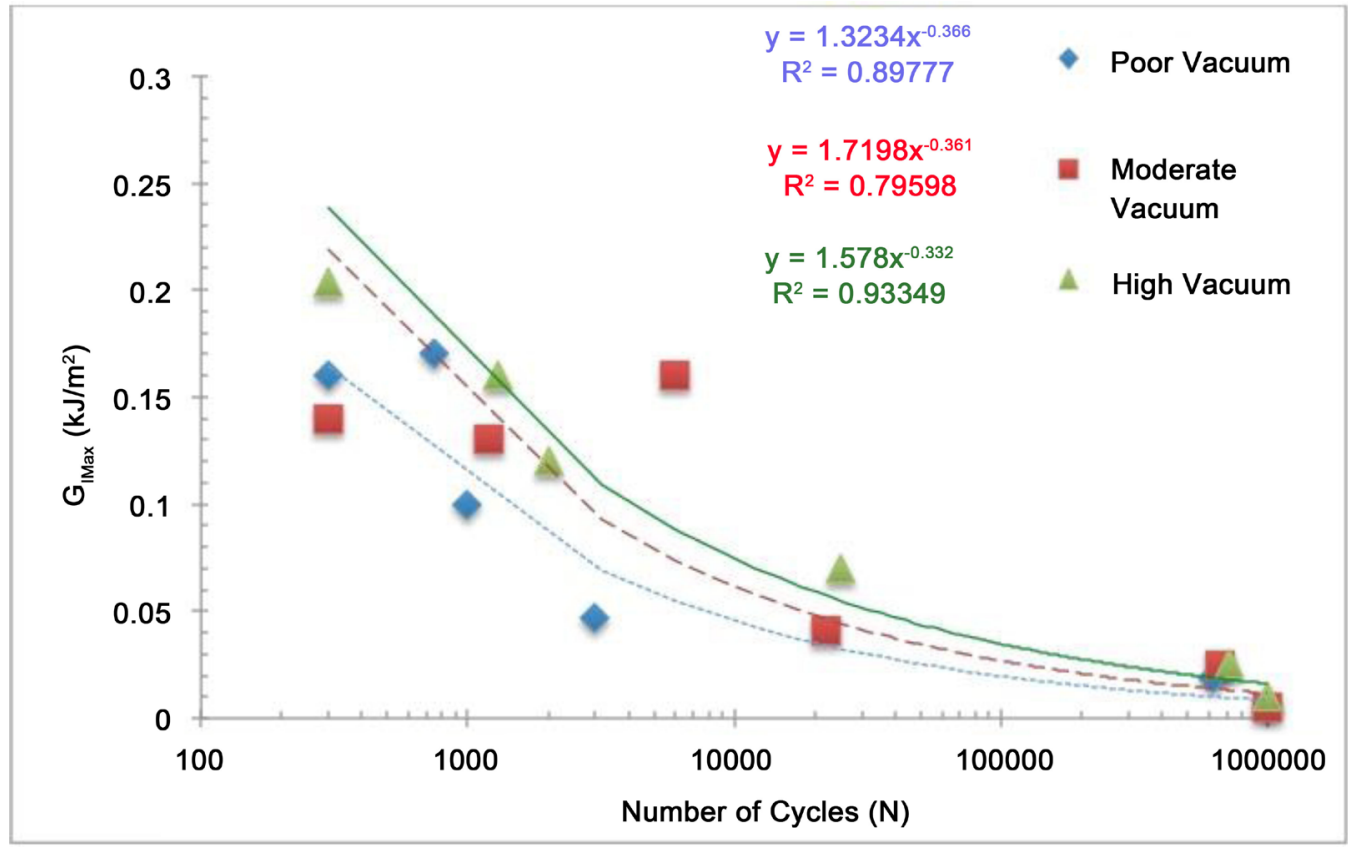

Figure 16. Mode I maximum cyclic strain energy release rate $G_{I \max }$ versus number of cycles. 

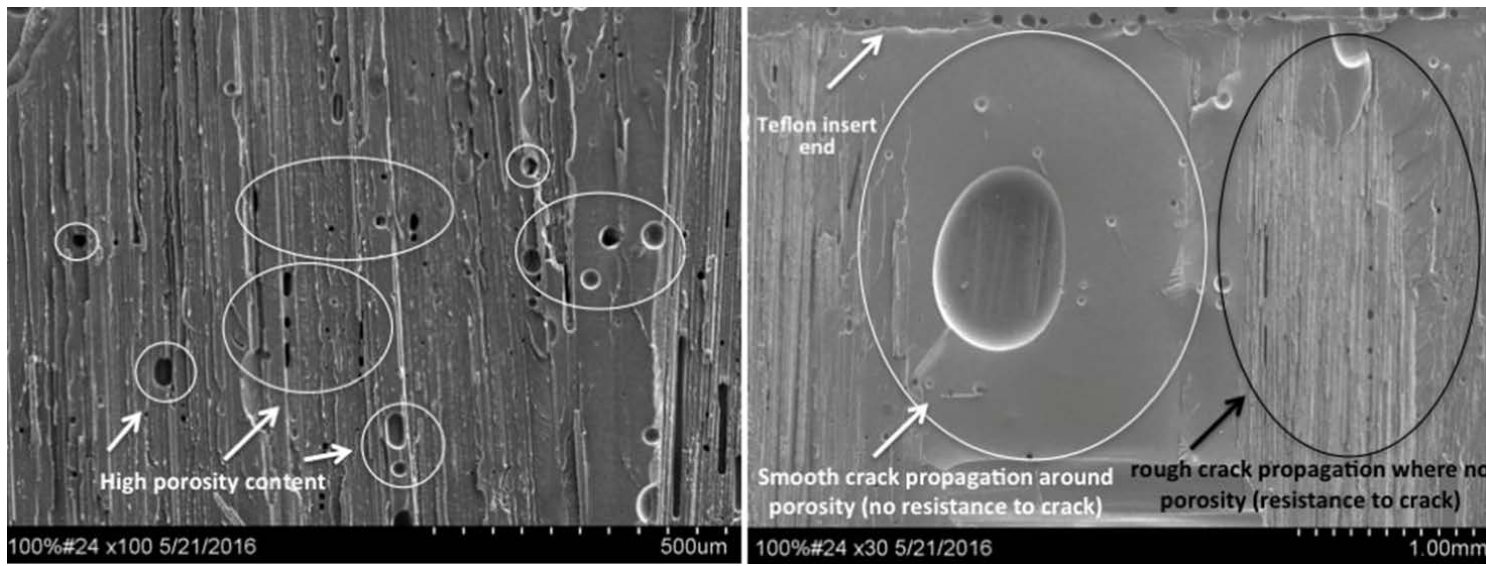

Figure 17. SEM micrographs of poor vacuum sample fracture surface under fatigue mode I.

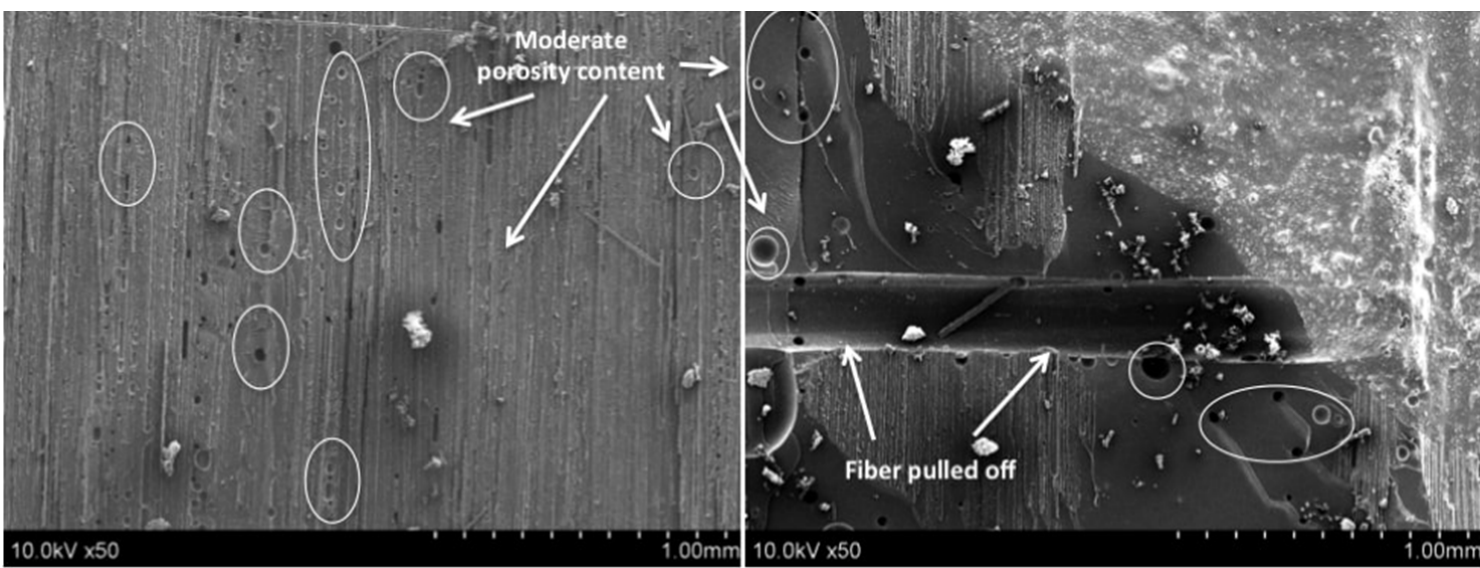

Figure 18. SEM micrographs of moderate vacuum sample fracture surface under fatigue mode I.

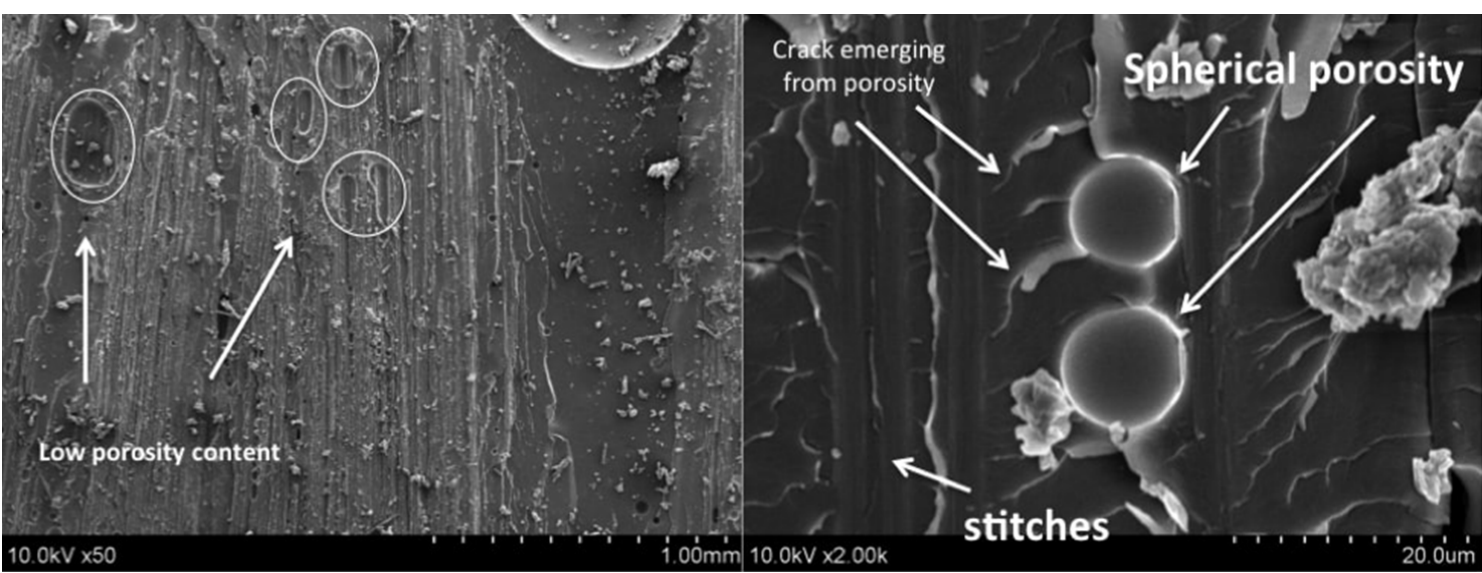

Figure 19. SEM micrographs of high vacuum sample fracture surface under fatigue mode I.

Fractographic micrographs showed that the initial fracture surface in static and fatigue tested samples were governed by the same mechanisms. But, fatigue has more features than static. For example, the fracture surfaces were covered by pieces of matrix material (debris) generated from grinding the matrix during cyclic load. The lower the vacuum, the higher the porosity content and the more the debris exist on the fracture surface. Also, more broken fibers and stitches and 
fiber pullouts were in the fatigue samples. Moreover, another feature caused by cyclic loading is the initiation and propagation of new cracks around the stitches and in the resin interlaminar layer, and more crack propagation from porosity in ramified shapes [10].

To summarize, correlating the three approaches in the mechanical testing proved that porosity is an effect on Mode I interlaminar fracture toughness: fractographic images showed that porosity content increased as the vacuum level decreased; Mode I static results represented in Figure 12 showed that the higher the vacuum (lower porosity content) the higher the force required to open the samples; the Mode I fatigue results shown in Figure 16, showed that the higher the vacuum (lower porosity content) the higher the fatigue life of the composites.

\section{Conclusions}

This study was undertaken to understand the effects of porosity on mechanical behavior and material properties of carbon fiber-reinforced polymer composite samples fabricated using hand lay-up. Non-destructive and destructive testing was applied. Both static and fatigue Mode I interlaminar fracture behavior and fractographic analyses were implemented. Several conclusions can be drawn from this study as follows:

- Nondestructive evaluation methods gave the trend in discontinuities or density variations that can be related to the porosity content. The averaging nondestructive evaluation results gave parameters that can be corralled to porosity, which seems to allow more accurate porosity percentages determination than the imaging nondestructive evaluation methods. The averaging nondestructive methods gave specific values reflecting porosity effects through-thickness. But, the imaging nondestructive evaluation methods contained many artifacts, which sometimes cannot be distinguished from porosity.

- Porosity led to a decrease in both Mode I static interlaminar fracture toughness and Mode I cyclic strain energy release rates fatigue life when vacuum level decreased. However, porosity's size, shape and location as well as fiber bridging, resin weight fraction and crack bridging, which all form randomly have dramatically affected the interlaminar properties no matter the vacuum level is. Hence, these factors produced overlapping in some samples among the three vacuum level results.

- Fractographic features drew relations between fracture surfaces and mechanical behavior and material properties of composite between panels fabricated at different vacuum levels, and between both Mode I static and fatigue.

- Serial sectioning exposed the composite's internal structure and provided a true idea about porosity's type, shape, size, distribution and location.

- A comparison between all methods conducted was made and presented in Table 1: features revealed by serial sectioning and fractography, static and fatigue results, and porosity percentages and parameters resulted from nonde- 
structive evaluation methods. Correlating all approaches in this study proved that porosity is an effect on Mode I static and fatigue interlaminar fracture toughness.

\section{Future Recommendations}

Based upon this study results, the teamwork of this manuscript is making the following recommendations for future research into the effects of porosity on mechanical behavior and material properties in fiber-reinforced composites.

- Fabricate polymer composite materials using other manufacturing processes such as pultrusion, vacuum infusion and autoclave molding. That is to see how porosity forms in different shapes, size, distribution and locations in other manufacturing methods, subsequently porosity can be classified.

- Conduct other mechanical testing. For example, interlaminar fracture tests such as shearing mode (mode II) and mixed mode, etc. That is in order to specify what mechanical and material properties are most affected by porosity.

- As for nondestructive evaluation, a large number of testing has been conducted in this study; but some physical measuring characteristics might limit some nondestructive evaluation methods. For example, fibers other than carbon might not be tested by thermography or eddy current because they are non-conductive.

- Develop a mathematical or finite element model of porosity effects on strength and stiffness of composites.

\section{Acknowledgements}

The main author, Mr. Hakim, gratefully acknowledges Omar Al-Mukhtar University-Libya, for giving him a scholarship to pursue Ph.D. at University of Dayton-USA. He is also grateful for the University of Dayton-USA and Fraunhofer-IKTS, Berlin, Germany for giving him the opportunity to work on a joint research program in Dayton and Berlin. University of Dayton funded the manufacturing process of carbon/epoxy composite samples and the mechanical testing under the supervision of Prof. Donaldson and Prof. Browning. FraunhoferIKTS, Berlin, Germany sponsored Mr. Hakim for a year and allowed him to use their most developed nondestructive evaluation facilities under the supervision of Prof. Meyendorf. Fraunhofer-IKTS who arranged for Mr. Hakim to conduct further nondestructive testing at other German academic and industrial institutions: TU Dresden, BAM, SURAGUS, and NANOTEST. Mr. Hakim is grateful for Fraunhofer-IKTS, Berlin's management who put quite a lot of efforts into this process in particular Mr. Drust and Ms. Wollgramm, as well as UDRI technicians. Moreover, Mr. Hakim would also like to thank Prof. Jain and Prof. Hoffman, Dr. Saied, Dr. El-Senussi Abu Fares, Dr. Akram Elegwel and Dr. Mousa Ahmida who were always available for guidance and support. Without the financial, academic and technical support of the mentioned hereinbefore Libyan, American and German entities and experts, it would have been very difficult for this research to achieve this success. 


\section{References}

[1] Burton, S., Jenkins, N., Sharpe, D. and Bossanyi, E. (2011) Wind Energy Handbook. 2nd Edition, Wiley. https://doi.org/10.1002/9781119992714

[2] Bhat, M.R., Binoy, M.P., Surya, N.M., Murthy, C.R.L. and Engelbart, R.W. (2012) Non-Destructive Evaluation of Porosity and Its Effect on Mechanical Properties of Carbon Fiber Reinforced Polymer Composite Materials. Review of Progress in Quantitative Nondestructive Evaluation AIP Conferences Proceedings, 1430, 1080 1087. https://doi.org/10.1063/1.4716341

[3] Abdelal, N. and Donaldson, S. (2013) The Effects of Voids on Delamination Behavior under Static and Cyclic Mode I and Mode II' 28 Technical Conference.

[4] Olivier, P., Cottu, J.P. and Ferret, B. (1995) Effects of Cure Cycle Pressure and Voids on Some Mechanical Properties of Carbon/Epoxy Laminates. Composites, 26, 509. https://doi.org/10.1016/0010-4361(95)96808-J

[5] ASTM Standard D5528 (2013) Mode I Interlaminar Fracture Toughness of Unidirectional Fiber-Reinforced polymer Matrix Composites. Am Soe Testing and Materials, West Conshohocken.

[6] ASTM Standard D6115 (2011) Mode I Fatigue Delamination Growth Onset of Unidirectional Fiber-Reinforced Polymer Matrix Composites. Am. Soc. Testing and Materials, West Conshohocken.

[7] Hakim, I., May, D., Abo Ras, M., Meyendorf, N. and Donaldson, S. (2016) Quantifying Voids Effecting Delamination in Carbon/Epoxy Composites: Static and Fatigue Fracture Behavior. Smart and Nondestructive Evaluation for Energy Systems, Proceedings of SPIE, Las Vegas, Vol. 9806, 98060H-1.

[8] Hakim, I., et al. (2016) The Effect of Manufacturing Conditions on Discontinuity Population and Fatigue Behavior in Carbon/Epoxy Composites. In Press in Conference of 43 rd Annual Review of Progress in Quantitative Nondestructive Evaluation, Atlanta.

[9] Whitney, J.M., Browning, C.E. and Hoogsteden, W. (1982) A Double Cantilever Beam Test for Characterizing Mode I Delamination of Composite Materials. Journal of Reinforced Plastic and Composites.

[10] Abdelal, N. (2013) Effect of Voids on Delamination Behavior under Static and Fatigue Mode I and II. Ph.D. Dissertation, University of Dayton, Dayton.

\section{Submit or recommend next manuscript to SCIRP and we will provide best service for you:}

Accepting pre-submission inquiries through Email, Facebook, LinkedIn, Twitter, etc. A wide selection of journals (inclusive of 9 subjects, more than 200 journals) Providing 24-hour high-quality service User-friendly online submission system Fair and swift peer-review system Efficient typesetting and proofreading procedure Display of the result of downloads and visits, as well as the number of cited articles Maximum dissemination of your research work

Submit your manuscript at: http://papersubmission.scirp.org/

Or contact msa@scirp.org 